\title{
APOA1/APOC3 Fusion Gene
}

National Cancer Institute

\section{Source}

National Cancer Institute. APOA1/APOC3 Fusion Gene. NCI Thesaurus. Code C99187.

A fusion gene that results from an inversion involving the $q$ arm of chromosome 11 that fuses the fourth exon of the APOA1 gene with the first intron of the APOC3 gene. This fusion is associated with combined apoA-I and apoC-III deficiency. The transcripts from this fusion gene do not produce functional apolipoproteins. 